\title{
Attitudes of Medical Students Towards Psychiatry in QMC (Bahawalpur) Pakistan
}

\author{
N MAQSOOD W ALI S NIAZ* HR CHAUDHRY* JAMALIK I AHMAD \\ Department of Psychatry, Bahaval Victoria Hospital, Quaid-e-Azam Medical College, Bahawalpur \\ *Deparment of Psychiatry. Fatima Jinnah Medical College/Sir Ganga Ram Hospital, Lahore \\ Correspondence to Dr. Niaz Maqsood, Consultant Psychiatrist.E mail:maqsood@hotmail.com
}

The present study is a comprehensive investigation of the attitude toward psychiatry from Quaid-e-Azam Medical College, Bahawalpur (Pakistan). A total of 538 students were studied using a 50-item Scale (ATP 30). Responses of the students were collected from classes of $1^{\text {st }}$ year and $4^{\text {th }}$ year and a comparison was calculated on year wise and gender wise basis. The results are presented and discussed.

Key words: Attitude, students, medical psychiatry, gender

Medical students appear to modify their attitudes and opinions toward different specialties as they go through medical school. ${ }^{2}$. Their attitudes toward psychiatry are very important for the future care of psychiatric patients and the recruitment of qualified graduates ${ }^{3}$ : Several surveys of U.S. medical students have been published in the U.S. literature ${ }^{4.5}$ and other surveys of medical students have appeared in the international literature $\mathrm{e}^{6,7.8}$.

The Indian subcontinent (India, Pakistan, Bangladesh, Nepal, Sri Lanka, Bhutan) contributes onethird of U.S international medical graduates (IMGs) in psychiatry residencies". Research on factors that potentially influence the choice of psychiatry as a medical specialty has been increased in recent decades, to postgraduate psychiatric training programs. Comprehensive reviews of the relevant literature are now available 4.10 .11 , and information about applicants to psychiatric residencies in non-English-speaking countries has become available in recent years ${ }^{12-13}$.

Scher et $\mathrm{al}^{14} \mathrm{x}$ ?ported results of a survey of 209 senior medical students from eight different U.S. medical schools, among which 19 students stated a preference for psychiatric postgraduate training. Those intending to undertake a residency in psychiatry were more likely than their peers to rate more positively the efficacy of psychiatric treatments, the gratification from psychiatric work, the adequacy of psychiatric conceptual models, and the quality of the psychiatric teaching. They also appreciated the holistic approach, which psychiatry takes to patients, the opportunity to get to know patients in depth, the breadth of the field and its interactions with other disciplines, and the recent advances in neurosciences.

Some authors ${ }^{15.16}$ believe that the general opinion of psychiatry is gradually improving, together with its social image in general. Dr. Nielsen developed a questionnaire with questions both from prior work and conventional wisdom. About half of the questions were stated in terms favorable to psychiatry. The other half was stated in negative form. Both open-ended and Likert type questions were included. Authorization and their results suggested that most students remained generally positive about the field of psychiatry, even though it was not their career choice $^{17}$. Where as, a negative attitude toward psychiatry or the psychiatrist's role has frequently been observed by a number of authors in different countries [U.S. ${ }^{4,16,18,19,20,}$ U.K $^{7,21,22,}$ France $^{23,}$ Australia ${ }^{24,25,}$ Saudi Arabia ${ }^{26,}$ Korea $^{27,}$ and $\mathrm{China}^{3}$ ]. Furthermore, several studies have shown that students' attitudes toward psychiatrists, psychiatric treatment, psychiatric patients, and psychiatry in general change significantly in a positive direction after their psychiatric training $28,29,30,31$ A variety of factors seem to affect medical students' attitudes toward psychiatry, and these can be divided in two main categories ${ }^{4}$. The first category includes factors that influence students before their entrance into medical school, such as demographic and personality characteristics ${ }^{4,32,33 \text {, cultural factors }}{ }^{34}$ the historical and social climate of a particular period of time $^{35}$. The second category includes factors that influence students during the medical school years, such as the medical school's attitude toward psychiatry, the view of non-psychiatric faculty about psychiatry and psychiatrists, and the undergraduate psychiatric education itself $f^{1,4,31,36}$.

In their study Pailhez \& Bulbena has classified factors that influence such attitudes directly in to three main categories: individual factors, factors related to medical school, and sociocultural factors ${ }^{36 .}$ Nielsen and Eaton $^{17}$ emphasized that "strong negative socializing pressure from peers, house staff, and non-psychiatric faculty were reported to be both common and effective in discouraging students interested in psychiatry." Sierles and Taylor felt that other variables, such as student attitudes and course characteristics, were less important ${ }^{2}$.

We set out to gain a better understanding of the attitudes and career preferences among Pakistani medical students. The aim was to gain insight into the learning process from the student's perspective. This information may assist in planning programs for increasing the interest of medical students in psychiatry and, optimistically, to direct more students toward psychiatry residency.

\section{Methodology:}

The study was conducted in Quaid-e-Azam Medical College Bahawalpur, in the year of 2004-2005.The sample 
consisted of 538 medical students consisting of 342 first year students and 196 fourth year students.

A five-point attitude scale (ATP 30) previously used in national $1^{35}$ and international ${ }^{30}$ studies and validated for measuring attitude toward psychiatry was distributed among students in their classrooms. The scale was originally developed and validated by Burra $^{30}$ for measuring attitudes of Canadian medical students and also used in Rawalpindi Medical College for the same purpose by F.A Minhas. The Scale consisted of 30 items with five response options for each item. Students were advised to respond on all 30 items by the most suitable option, which represents their level of agreement or disagreement about the statement. The options consisted of "Strongly Agree, Agree, Neutral, Disagree, and Strongly Disagree." As the scale was developed to measure both positive and negative attitudes towards various aspect of psychiatry, it consisted of 15 items measuring positive and 15 items measuring negative attitude toward psychiatry. Responses were scored as 1 to 5 for items measuring negative attitude where as 5 to 1 for items measuring positive attitude.

A high total score on the scale represents positive attitude of respondents about psychiatry and its disciplines where as low total score indicates negative attitude. For computation and analysis of the data in the study SPSS (statistical package for social sciences) was utilized. Calculations were made for mean scores and significance test were applied to check out significance of difference in means.

\section{Results:}

The sample consisted of 538 medical students consisting of 342 first year students and 196 fourth year students. There were 240 male and 298 female students. The year and gender wise distribution is presented in table -1 .

Table I: Year and gender wise distribution of sample

\begin{tabular}{llll}
\hline Class & Gender & \multicolumn{2}{c}{ Total } \\
\cline { 2 - 3 } & Male & Female & \\
\hline First year & 144 & 198 & 342 \\
Fourth year & 96 & 100 & 196 \\
Total & 240 & 298 & 538 \\
\hline
\end{tabular}

Analysis was made by clustering all the 30 items in four groups assuming that each group measures attitudes of students towards a specific aspect of psychiatry. The classification of items adopted here was that utilized by F.A Minhas at Rawalpindi Medical College ${ }^{35}$. Items on ATP 30 were divided into four categories as (a) four items measuring attitude toward psychiatric patient and psychiatric illness (b) eleven items measuring attitude toward psychiatry and psychiatric illness (c) seven items measuring attitude toward psychiatric knowledge and teaching (d) eight items measuring attitude towards psychiatric treatment and psychiatric hospitals. Results are shown in tables II, III, IV, and V.

Table: II, Mean response for items measuring attitude toward psychiatric patients and psychiatric illness.

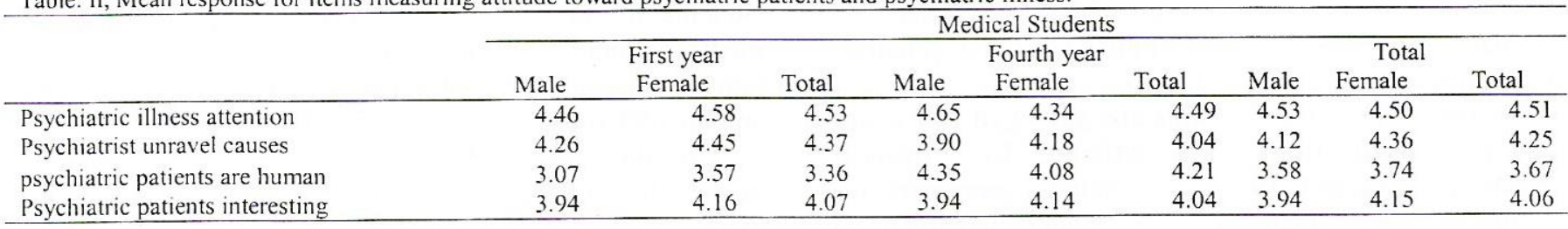

Table: IIl, Mean responses of the sample-measuring attitude towards psychiatrists and psychiatry

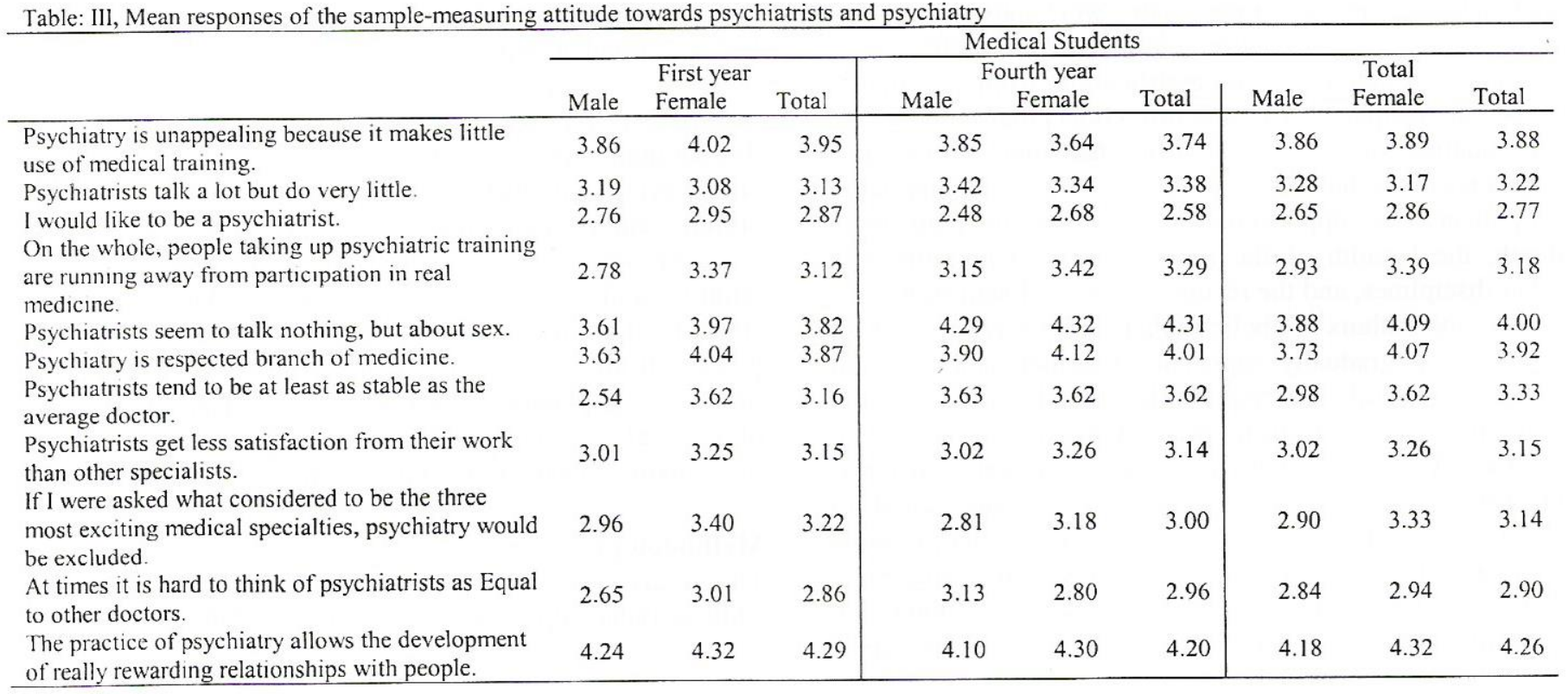


Table: IV, Mean responses of the sample-measuring attitude towards psychiatric knowledge and teaching.

\begin{tabular}{|c|c|c|c|c|c|c|c|c|c|c|}
\hline & \multicolumn{10}{|c|}{ Medical Students } \\
\hline & \multicolumn{3}{|c|}{ Male and Female } & \multicolumn{3}{|c|}{ Male and Female } & \multicolumn{4}{|c|}{ Male and Female } \\
\hline & Male & Female & Total & Male & Female & Total & Male & & Female & Total \\
\hline $\begin{array}{l}\text { Psychiatric teaching increases our } \\
\text { understanding of medical and surgical patients. }\end{array}$ & 3.47 & 3.93 & 3.74 & 3.75 & 3.60 & 3.67 & & 3.58 & 3.82 & 3.71 \\
\hline $\begin{array}{l}\text { The majority of students report that their } \\
\text { psychiatric undergraduate training has been } \\
\text { valuable. }\end{array}$ & 3.47 & 3.51 & 3.49 & 3.29 & 3.66 & 3.48 & & 3.40 & 3.56 & 3.49 \\
\hline $\begin{array}{l}\text { Psychiatry has very little scientific information } \\
\text { to go on. }\end{array}$ & 3.14 & 3.17 & 3.16 & 3.25 & 3.02 & 3.13 & & 3.18 & 3.12 & 3.15 \\
\hline $\begin{array}{l}\text { These days psychiatry is the most important } \\
\text { part of the curriculum in medical schools. }\end{array}$ & 3.21 & 3.39 & 3.32 & 2.85 & 3.42 & 3.14 & & 3.07 & 3.40 & 3.25 \\
\hline $\begin{array}{l}\text { Psychiatry is so unscientific that even } \\
\text { psychiatrists can't agree to scientific basis }\end{array}$ & 3.12 & 3.10 & 3.11 & 3.02 & 3.00 & 3.01 & & 3.08 & 3.07 & 3.07 \\
\hline $\begin{array}{l}\text { Most of so called facts in psychiatry are really } \\
\text { just vague speculations. }\end{array}$ & 3.26 & 3.29 & 3.28 & 3.60 & 3.44 & 3.52 & & 3.40 & 3.34 & 3.37 \\
\hline $\begin{array}{l}\text { Psychiatry is so amorphous that it cannot really } \\
\text { be taught effectively. }\end{array}$ & 2.96 & 3.17 & 3.08 & 3.29 & 2.62 & 2.95 & & 3.09 & 2.99 & 3.03 \\
\hline
\end{tabular}

Table V: Attitude towards psychiatric treatment and psychiatric hospitals.

\begin{tabular}{|c|c|c|c|c|c|c|c|c|c|}
\hline & \multicolumn{9}{|c|}{ Medical Students } \\
\hline & \multicolumn{3}{|c|}{ First year } & \multicolumn{3}{|c|}{ Fourth year } & \multicolumn{3}{|c|}{ Total } \\
\hline & Male & Female & Total & Male & Female & Total & Male & Female & Total \\
\hline $\begin{array}{l}\text { Psychiatric hospitals are little more than } \\
\text { prisons }\end{array}$ & . 2.96 & 2.71 & 2.81 & 3.54 & 3.02 & 3.28 & 3.19 & 2.81 & 2.98 \\
\hline $\begin{array}{l}\text { It is quite easy for me to accept the efficacy of } \\
\text { psychotherapy. }\end{array}$ & 3.64 & 3.54 & 3.58 & 3.77 & 3.70 & 3.73 & 3.69 & 3.59 & 3.64 \\
\hline $\begin{array}{l}\text { The practice of psychotherapy basically is } \\
\text { fraudulent since there is no strong evidence } \\
\text { that is effective. }\end{array}$ & 3.53 & 3.52 & 3.52 & 3.48 & 3.68 & 3.58 & 3.51 & 3.57 & 3.54 \\
\hline $\begin{array}{l}\text { With the forms of therapy now at hand most } \\
\text { psychiatric patients improve. }\end{array}$ & 3.68 & 3.64 & 3.65 & 3.54 & 3.87 & 3.71 & 3.62 & 3.71 & 3.67 \\
\hline $\begin{array}{l}\text { Psychiatric hospitals have a specific } \\
\text { contribution to make to the treatment of the } \\
\text { mentally ill. }\end{array}$ & 3.71 & 3.30 & 3.47 & 3.40 & 3.40 & 3.40 & 3.58 & 3.34 & 3.45 \\
\hline $\begin{array}{l}\text { In recent years psychiatric treatment has } \\
\text { become quite effective. }\end{array}$ & 3.92 & 4.04 & 3.99 & 3.85 & 4.04 & 3.95 & 3.89 & 4.04 & 3.97 \\
\hline
\end{tabular}

\section{Discussion:}

In our study Stur.ents from both first and fourth year revealed highly positive attitude toward items measuring attitude toward psychiatric patients and psychiatric illness. Female students have more positive attitude toward item "Psychiatric patients interesting." The area these items representing is adding more in the development of positive attitude of medical students towards Psychiatry. Furthermore the students of $4^{\text {th }}$ year have a more positive attitude toward item "Psychiatric patients are human" which indicates that students' attitude can be more positive if they are taught about humanity and importance of psychiatric illness. These findings therefore, corroborate the results of Garyfallos et $a 1^{15}$. Balon et $\mathrm{al}^{16}$ and Pailhez et $\mathrm{al}^{36}$. that the opinions of psychiatry have improved.

Compared with the Nielsen and Eaton study ${ }^{17}$, what has changed over the last 15 years, is that the students revealed a positive attitude toward psychiatric patients and psychiatric illness and that the psychiatry has progressed and is rapidly expanding. Some items revealed extra ordinary positive attitude of students toward Psychiatry like "The practice of psychiatry allows the development of really rewarding relationships with people". This reveals that students' attitude can be highly influenced by teaching them about the importance of self-respect and popularity in life. Response rates to the item like "Psychiatry is unappealing because it makes little use of medical training" with a positive attitude of both classes tells that the old and outworn concepts of students about Psychiatry is changed.

Some of the items measuring attitude towards psychiatrists and psychiatry indicates a positive attitude of whole sample in general but more positive attitude of $4^{\text {th }}$ year students in particular indicates that these area are contributing well in the development of positive attitude in medical students toward psychiatry. In the students opinion the psychiatrists, should be more focused during teaching psychiatry to students, as these aspects have a potential factor for attitude change. Furthermore, females are more positive than male students on these aspects of Psychiatrist and Psychiatry. The items like "Psychiatrists tend to be at least as stable as the average doctor" are included in these potential aspects, while the attitude of $1^{\text {st }}$ year is neutral and $4^{\text {th }}$ year has positive tendency toward Psychiatry. This positive skew of the medical students towards psychiatry is consistent with the results of 
conducted by Alexander and Kumaraswamy ${ }^{6}$ at Kasturba Medical College in Manipal, India. This observation should be worked out to develop and enhance more positive attitude of medical students toward Psychiatry.

Medical students have positive attitude toward knowledge and teaching of Psychiatry i.e., "Psychiatric teaching increases our understanding of medical and surgical patients" which can further utilized to develop their interest in different aspects of Psychiatry." The majority of students report that their psychiatric undergraduate training has been valuable." About the aspects of Psychiatric teaching, which represent importance of Psychiatry as science, student's attitude was overall neutral. Some items about teaching of psychiatry revealed neutral aspects but interestingly females have much greater tendency to develop positive attitude toward these aspects like "These days psychiatry is the most important part of the curriculum in medical schools". About myths in Psychiatry like "Most of so called facts in psychiatry are really just vague speculations" $4^{\text {th }}$ year responses were more positive revealing that if these aspect of psychiatry are worked properly, they will more helpful in development of positive attitude of medical students toward Psychiatric teaching and knowledge. This replicates the results of the Greek study by Garyfallos et $\mathrm{al}^{15}$ that there are significant changes in the Greek society about attitude towards psychiatry and psychiatric education in medical schools/ colleges is a significant determinant in molding student's attitudes towards psychiatry. Student's attitude influence not only psychiatric recruitment but also the ability of future nonpsychiatric physicians to identify and appropriately refer patients with psychiatric disorders 7,17 . This ability is essential especially for physicians who work in primary care centers.

Medical students admitted effectiveness of psychiatric treatment as they have clearly positive attitude on item "In recent years psychiatric treatment has become quite effective". These items about Psychiatric treatment and hospital revealed positive attitude of $4^{\text {th }}$ year indicating these aspects are important and effective in developing positive attitude of students. The international medical students also registered this solid positive opinion, during the study of Rao et $\mathrm{al}^{9}$ in India and Zimbabwe. In regards to this positive attitude it is suggested in the light of international studies ${ }^{37,38,39}$. it should be enhanced with the available evidence of the efficacy of various biological and psychotherapeutic treatments for primary psychiatric patients. Through exposure to consultation liaison psychiatry $^{40}$ experience, it could demonstrate the usefulness and importance of basic psychotherapeutic skills, which can be applied to all medical patients as well. Involvement with not only the acutely disturbed psychiatric patients but also without patients who represent "successful" cases as suggested by Clardy et $\mathrm{al}^{41}$ and Pessar $^{42 .}$ may challenge commonly held pessimistic attitudes and may contribute towards inspiring a more realistic and positive attitude in future practitioners who choose disciplines other than psychiatry.

\section{Conclusions:}

The image of psychiatry among medical students is fairly positive and improving with time. Now psychiatry is viewed as a valid, progress-making branch of medical sciences and as a helping discipline. At the same time, while the attitude of our medical students toward psychiatry may be positive, they are likely not to have had as much exposure to the field, as the US and European medical graduates. Further research is needed to compare the opinions of medical students towards psychiatry, the factors influencing the choosing of a specialty, and the process of recruitment of students into psychiatry.

\section{References:}

1. Lee EK, Kaltreider N, Crouch J: Pilot study of current factors influencing the choice of psychiatry as a specialty. Am J Psychiatry 1995; 152:1066-1069

2. Sierles FS, Taylor MA: Decline of U.S. medical student career choice of psychiatry and what to do about it. Am J Psychiatry 1995; 152:1416-1426.

3. Pan PC, Lee PWH, Lieh-Mak FF: Psychiatry as compared to other career choices: a survey of medical students in Hong Kong. Med Educ 1990; 24:251-257

4. Eagle PF, Marcos LR: Factors in medical students' choice of psychiatry. Am J Psychiatry 1980; 137:423-427.

5. Weiss man S, Bashook P: An analysis of changing patterns of American medical student career selection of psychiatry. Journal of Psychiatric Education 1980; 4:225-234

6. Alexander PJ, Kumaraswamy N: Senior medical students' attitude towards psychiatry: relationship with career interest. Indian Journal of Psychiatry 1993; 35:221-224

7. Das M, Chandrasena R: Medical students' attitude toward psychiatry. Can J Psychiatry 1988; 33:767-783

8. Kaplan De-Nour A, Weisstub EB: Attitudes of medical students towards people with emotional problems. Israel J Psychiatry Relat Sci 1981; 18:215-220

9. Rao NR, Meinzer AE, Manley M, Chagwedera I: International Medical Students' Career Choice, Attitudes Toward Psychiatry, and Emigration to the United States: Examples From India and Zimbabwe. Academic Psychiatry $1998 ; 22: 117-126$

10. Brockington I, Mumford D: Recruitment into psychiatry. $\mathrm{Br}$ J Psychiatry 2002; 180:307-312

11. Weissman S: Recruitment and workforce issues in late $20^{\text {th }}$ century American psychiatry. Psychiatr Q 67; 1996:125-137

12. Baptista T, Perez CS, Mendez L, et al: The attitudes toward psychiatry of physicians and medical students in Venezuela. Acta Psychiatr Scand 1993; 88:53-59.

13. Strebel B, Obladen M, Lehmann E, Gaebel W: Attitude of medical students to psychiatry. A study with the German translated, expanded version of the ATP-30. Nervenarzt. 2000 Mar;71(3):205-12.

14. Scher ME, Carline JD, Murray J: Specialization in psychiatry: what determines the medical student's choice pro or con. Compr Psychiatry 1983; 24:459-468 
15. Garyfallos G, Adamopoulou A, Lavrentiadis G, et al: Medical students' attitudes toward psychiatry in Greece: an eıghtyear comparıson. Acad Psychiatry 1998; 22:92-97

16. Balon R, Franchini GR, Freeman PS, et al: Medical students attitudes and views of psychiatry: 15 years later. Acad Psychiatry 1999; 23:30-36

17. Nielsen AC, Eaton JS: Medical students attitudes about psychiatry: implications for psychiatric recruitment. Arch Gen Psychiatry 1981; 38:1144-1154

18. Zimny GH, Sata-Lindenbergh S: Influence of factors before and during medical school on choice of psychiatry as a specialty. Am J Psychiatry 1986; 143:77-80

19. Funkenstein D: Medical Students, Medical Schools and Society During Five Eras: Factors Affecting the Career Choices of Physicians, 1958-1976. Cambridge, MA, Ballinger, 1978

20. Yager J, Lamotte K, Nielsen AC, et al: Medical students' evaluation of psychiatry: a cross-country comparison. Am J Psychiatry 1982; 139:1003-1009.

21. Ghadirian AM Engelsmann F: Medical students' interest in and attitudes toward psychiatry. Journal of Medical Education 1981; 56:361-362

22. Silver L, Brunstetter R: Premedical education and the medical school admission process: factors in-fluencing psychiatry specialty choice. Journal of Psychiatric Education 1980; 4:327-341

23. Samuel-Lajeunesse B, Ichou P: French medical students' opinion of psychiatry. Am J Psychiatry 1985; 142:14621466

24. Malhi GS, Parker GB, Parker $\mathrm{K}$, et al: Attitudes toward psychiatry among students entering medical school. Acta Psychiatr Scand 2003; 107:424-429

25. Yellowlees P. Vizard T, Eden J: Australian medical students' attitudes towards specialities and specialists. Med J Aust 1990; 152:587-592

26. Sou. HE, Raoof AM: Attitude of medical students towards psychiatry. Med Educ 1992; 26:38-41

27. Koh KB: Medical students' attitudes toward psychiatry in a Korean medical college. Yonsei Med J 1990; 31:60-64

28. Ghadirian A, Engelsmann F: Medical students' attitude toward psychiatry: a ten-year comparison. Med Educ 982; $16: 39-43$
29. Rahim A, El-Assera A: Saudi medical students' attitudes toward psychiatry. Annals of Saudi Medicine 1989; 9:190 194

30. Burra P, Kalin R, Leichner P, et al: The ATP 30-a scale for measuring medical students' attitudes to psychiatry. Med Educ 1982;16:31-38

31. Wilkinson DG, Greer S, Toone BK: Medical students' attitudes toward psychiatry. Psychol Med 1983; 13:185-192

32. Walton $\mathrm{H}$ : Personality correlates of a career choice interest in psychiatry. Br J Psychiatry 1969;115:211-219

33. Toone B, Murray R, Clare A, et al: Psychiatrists models of mental illness and their personal backgrounds. Psychol Med 1979; 9:165-178

34. Shokoohi-Yekta M, Retish P: Attitudes of Chinese and American male students toward mental illness. Int J Soc Psychiatry 1991; 87:192-200

35. Minhas F. A, Mubbashar M.H: Attitudes of medical students towards psychiatry in Pakistan. JCPSP Jan, 2000; Vol. 10 (2): 69-72.

36. Pailhez G, Bulbena A., Coll J. et al: Attitude and Views on Psychiatry: A Comparison Between Spanish and U.S. Medical Students. Academic Psychiatry 2005, 29: 82-91.

37. Zaimes JMS, Thompson TL; Opportunities for consultationliaison(medical-surgical) psychiatrists to enhance residency recruitment. Psychosomatics 1994; 35; 423-426.

38. Stoudemire A: Quo Vadis, psychiatry? Psychosomatics 2000; 41: 206-209.

39. Galeazzi GM, Secchi C, Currci P ; Current Factors Affecting the Choice of Psychiatry as a Specialty: An Italian Study. Academic Psychiatry 2003; 27: 74-81.

40. Ali W: Consultation Liaison Psychiatry, In Hayat Shaheed Teaching Hospital Peshawar. Journal of College of Physician and Surgeons of Pakistan, Vol, 9 No, 2, February 1999, 85--87.

41. Clardy JA, Thrush CR, Guttenberg VT, et al: The junior year psychiatric clerkship and medical students' interest in psychiatry: academic Psychiatry 2000; 24: 35-40.

42. Pessar LF: Ambulatory care teaching and the psychiatric clerkship. Academic Psychiatry 2000; 24: 61-67. 